\title{
BMI open Is a high level of general practitioner consultations associated with low outpatients specialist clinic use? A cross-sectional study
}

\author{
Trygve S Deraas, ${ }^{1,2}$ Gro R Berntsen, ${ }^{2,3}$ Toralf Hasvold, ${ }^{2}$ Unni Ringberg, ${ }^{2}$ \\ Olav Helge Førde 2
}

To cite: Deraas TS, Berntsen GR, Hasvold T, et al. Is a high level of general practitioner consultations associated with low outpatients specialist clinic use? A cross-sectional study. BMJ Open 2013;3: e002041. doi:10.1136/ bmjopen-2012-002041

- Prepublication history and additional material for this paper are available online. To view these files please visit the journal online (http://dx.doi.org/10.1136/ bmjopen-2012-002041).

Received 31 August 2012 Revised 27 November 2012 Accepted 10 December 2012

This final article is available for use under the terms of the Creative Commons Attribution Non-Commercial 2.0 Licence; see http://bmjopen.bmj.com

\footnotetext{
${ }^{1}$ Center of Clinical Documentation and Evaluation, Northern Norway Regional Health Authority, Tromsø, Norway ${ }^{2}$ Department of Community Medicine, University of Tromsø, Tromsø, Norway ${ }^{3}$ Norwegian Centre for Integrated Care and Telemedicine, University Hospital of North Norway, Tromsø, Norway
}

\section{Correspondence to} Dr Trygve S Deraas; trygve.deraas@uit.no

\section{ABSTRACT}

Objective: To examine if increased general practice activity is associated with lower outpatient specialist clinic use.

Design: Cross-sectional population based study.

Setting: All 430 Norwegian municipalities in 2009. Participants: All Norwegians aged $\geq 65$ years ( $n=721915 ; 56 \%$ women-15\% of the total population). Main outcome measure: Specialised care outpatient clinic consultations per 1000 inhabitants (OPC rate). Main explanatory: general practitioner (GP) consultations per 1000 inhabitants (GP rate).

Results: In total, there were 3339031 GP consultations (57\% women) and 1757864 OPC consultations (53\% women). The national mean GP rate was $4625.2 \mathrm{GP}$ consultations per 1000 inhabitants (SD 1234.3) and the national mean OPC rate was 2434.3 per 1000 inhabitants (SD 695.3). Crude analysis showed a statistically significant positive association between GP rates and OPC rates. In regression analyses, we identified three effect modifiers; age, mortality and the municipal composite variable of 'hospital status' (present/not present) and 'population size' (small, medium and large). We stratified manually by these effect modifiers into five strata. Crude stratified analyses showed a statistically significant positive association for three out of five strata. For the same three strata, those in the highest GP consultation rate quintile had higher mean OPC rates compared with those in the lowest quintile after adjustment for confounders $(p<0.001)$. People aged $\geq 85$ in small municipalities had approximately $30 \%$ lower specialist care use compared with their peers in larger municipalities, although the association between GP-rates and OPC-rates was still positive.

Conclusions: In a universal health insurance system with high GP-accessibility, a health policy focusing solely on a higher activity in terms of GP consultations will not likely decrease OPC use among elderly.

\section{INTRODUCTION}

Future healthcare utilisation might escalate as a consequence of biomedical innovations,

\section{ARTICLE SUMMARY}

Article focus

- The majority of ecological studies suggest that proxies for higher primary healthcare (PHC) accessibility such as primary care physician (PCP) density and PCP/specialist ratio are associated with lower hospital use.

- Studies on the association between PHC utilisation and secondary healthcare utilisation are lacking.

- The present cross-sectional study examines the association between general practice utilisation and secondary care outpatient clinics utilisation among the elderly.

\section{Key messages}

- Higher general practice consultation rate is associated with more outpatient secondary care use in a public financed healthcare system with low out-of-pocket expenses.

- Legal and practical access to the existing individual-level and system-level healthcare unit data are needed to examine the role of PHC for secondary care utilisation.

Strengths and limitations of this study

- Complete national age and sex stratified data of all GP consultations and secondary care outpatient clinic consultations among elderly over 65 is a strength of the study.

- Aggregated data allowing for analysis and conclusions to be drawn at the municipal level where PHC is administered is a study strength.

- Analyses were adjusted for several municipal level confounders, but lack of individual-level data made it impossible to adjust for individuallevel confounders, such as morbidity, which is a limitation.

more informed patients and population ageing, which leads to a higher proportion of chronically ill individuals. Specialist healthcare (SHC) uses a major and increasing proportion of healthcare budgets, so 
rationing of these services is a priority in most countries. Governments, ${ }^{1}{ }^{2}$ the $\mathrm{WHO}^{3}$ and the US employers ${ }^{4}$ argue for a strengthening of primary healthcare (PHC) to enhance chronic care and to better control healthcare expenditure.

Historically, Norway has a well-developed PHC in a universal health insurance system. ${ }^{5}$ Nevertheless, variations in hospital use, ${ }^{6}$ general practitioner (GP) referral rates $^{7}$ and consultation costs ${ }^{8}$ are reported at physician, municipality and regional levels. A patient list system was introduced in 2001, partly to strengthen access to GPs and in connection with the newly implemented coordination reform it has been suggested to increase the number of GP's to ease pressure on the hospitals. Early detection of disease, and improved monitoring, care and treatment in general practice may decrease or increase the patient need for outpatient clinic (OPC) or private specialist appointments. ${ }^{9}$ This depends on GPs' threshold for referrals, reflecting the diagnostic, organisational and therapeutic armamentarium in their local primary care setting.

The Norwegian coordination reform assumes that care for chronically ill, elderly people can be less fragmented and less expensive through the substitution of hospital use by enhanced primary care. ${ }^{10}$ The main measures are increase in GP capacity and reorganisation of the cooperation both within and between the levels of healthcare.

An OPC is by far the most frequent form of contact between GPs and hospitals in Norway, because the OPC consultations outnumber the hospital admission rate by a factor close to five. ${ }^{11}$ Findings, mostly from American ecological, macro-level studies, indicate that in large geographical areas (countries and states) proxies for PHC accessibility, is associated with better overall access to healthcare, lower healthcare expenses and hospital use and improved health outcomes. ${ }^{12}{ }^{13}$ However, primary care seems to have more impact in societies with higher social inequalities and at higher levels of aggregation. ${ }^{13-15}$ We have not identified any previous studies investigating the association of direct measures of GP activity on secondary care utilisation. Thus, the question of whether GP-consultation rates are associated with lower OPC-consultation rates, which is the most common entry into secondary care, is currently unknown.

In the current study we had access to a national database including all GP consultations and all OPC consultations in Norway in 2009, which was the first year with almost complete data from private specialists.

The aim of this cross-sectional study was to examine the hypothesis that more general practice visits are associated with reduced use of specialised care by (1) exploring the association between rates of GP and OPC consultations among people aged $>65$ in Norway and (2) studying the effect modification of case-mix factors (age, sex and mortality) and barriers to secondary care (travel time to hospital and municipal hospital status).

\section{METHODS}

\section{Materials}

This 1-year, total population-based, cross-sectional study included all Norwegians aged $\geq 65$ years $(n=721915 ; 56 \%$ women-15\% of the total population) in 2009. As we had no access to individual-level data, we chose to use aggregated data which was grouped according to Norwegian municipality of residence $(n=430)$, sex and the following age groups: $65-69,70-74,75-79,80-84,85-89$ and $\geq 90$. This was the highest data granularity available from public registries. One of the principal aims of the research was to examine the effect of age on associations. Hence, rather than calculate age-standardised rates, a dataset was generated of 5145 units of observation, based on the 430 municipalities multiplied by 12 age/sex groupings. Analysis of the data using this structure allowed us to examine the effect modification of age and sex, something which is not possible with age-standardised and sex-standardised data which is common in this field. Information on GP consultation rates was missing for 46 rows (706 individuals). We linked data from the following:

1. The Norwegian Patient Registry: OPC rate defined as the total number of both public and private OPC consultations in 2009 per 1000 inhabitants for each unit of analysis;

2. Statistics Norway: mortality, socioeconomic variables;

3. The Norwegian Health Economics Administration (HELFO): GP rate defined as the total number of GP office and out-of-hours casualty clinic consultations per 1000 inhabitants in 2009, in each unit of analysis. The data were checked by hospitals and the Norwegian Patient Registry and underwent an internal quality check mainly based on comparisons with the previous year's data and internal consistency. The different data from Statistics Norway are derived from national public registries of all the citizens living in Norway.

\section{Statistical methods}

The outcome variable (OPC rate) had a Poisson distribution that approximates a normal distribution when the probability for the outcome is high $(>5 \%)$. Thus, we manually built a linear regression model in SPSS (Statistical Package for Social Sciences) V.16 and SAS (Statistical Analysis System) V.9.2. To obtain as many percentile groups as possible to visualise threshold effects, while avoiding unstable results due to small numbers in each group, we classified our main explanatory variable, GP rate into quintiles. GP quintile 1 represented the lowest $20 \%$ and GP quintile 5 the highest $20 \%$ of the GP rate within each age group, thereby making age adjustment in analyses unnecessary. Table 1 describes the exact operationalisation and impact of several variables known to influence healthcare use. ${ }^{16}$

Where bivariate correlation between the adjustment variables had a Pearson correlation coefficient $\geq 0.7$, the variables were included as a joint composite variable. In the final model trends in the outcome across GP quintiles were tested by comparing the difference in annual 
Table 1 Description and role in analyses of explanatory variables

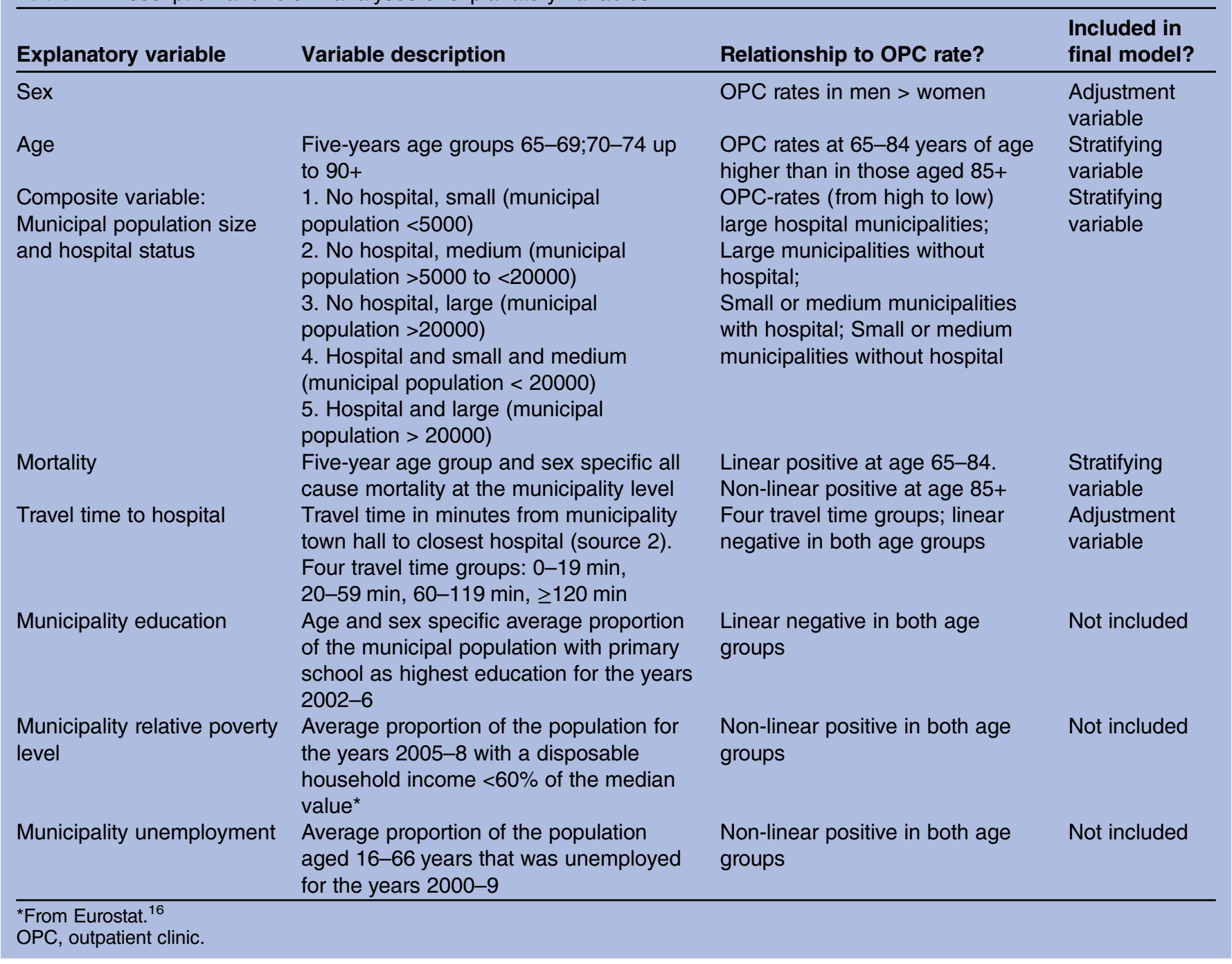

Least Square means between the first and last quintiles using independent samples t test.

The number of individuals ( $\mathrm{n}$ ) falling within the 5145 units of analysis varied between 1 and 10414 (mean 140.5). To ensure that those units containing few individuals did not have an unduly large influence on the results, all analyses were weighted by $n$. We did the analysis using a formalised evaluation of effect modification based on both statistical significance and policy relevance, in line with previous work. ${ }^{17}$ Policy relevance was a priori defined as a more than $15 \%$ change (365 OPC consultations per 1000 inhabitants) compared with the reference. Confounding was defined as a change in the predicted least square means of the relationship between the main explanatory and outcome variable of $>10 \%{ }^{18}$

The estimates of both GP and OPC rates in the 12 sex and age groups were expected to correlate within each municipality. To account for this, we adjusted for municipality by adding it to the model as a random effect variable. Finally, we checked that the distribution of the standardised residuals for both the intermediate model (main variables, age and sex) and the final model were normally distributed.

\section{RESULTS}

In total, there were 3339031 GP consultations $(56 \%$ women) and 1757864 OPG consultations $(53 \%$ women) over the 12-month period. The mean GP rate was 4625.2 GP consultations per 1000 inhabitants (SD 1234.3) and the mean OPC rate was 2434.3 per 1000 inhabitants (SD 695.3). The national distribution of population, GP rates and OPC rates by five GP quintiles and strata is given in table 2 .

In crude analysis, there was a statistically significant positive relationship between GP rates and OPG rates (data not shown).

The association between the GP rate and the OPC rate was modified by age, mortality and the composite variable of municipal 'hospital status' ( present/not present) and 'population size' (small, medium, large). We stratified manually by these effect modifying variables, 
Table 2 Descriptives of outcome, explanatory and stratifying variables

\begin{tabular}{|c|c|c|c|c|c|c|c|}
\hline \multirow[b]{2}{*}{ Age and municipality type } & \multicolumn{7}{|c|}{ GP quintile } \\
\hline & $\overline{1}$ & 2 & 3 & 4 & 5 & All & p Value \\
\hline \multicolumn{8}{|l|}{ Rate of OPC consultations (visits/1000 inhabitants) } \\
\hline \multicolumn{8}{|l|}{ Men } \\
\hline 65-84, small and medium+large non-hospital & 2130 & 2306 & 2286 & 2353 & 2420 & 2276 & $<0.000^{*}$ \\
\hline $65-84$, large, w/hospital & 2839 & 3015 & 2924 & 3229 & 3138 & 3050 & $<0.000$ \\
\hline $85+$, small & 1607 & 1644 & 2019 & 1890 & 2071 & 1873 & $<0.000$ \\
\hline $85+$, medium and large & 2024 & 2153 & 3029 & 2772 & 2946 & 2761 & $<0.000$ \\
\hline $85+$, medium and large, highest mortality & 1929 & 3209 & 3230 & 2624 & 2693 & 2754 & $<0.000$ \\
\hline All & 2022 & 2237 & 2310 & 2390 & 2352 & 2230 & $<0.000$ \\
\hline \multicolumn{8}{|l|}{ Women } \\
\hline 65-84, small and medium+large non-hospital & 1938 & 1979 & 1997 & 2025 & 2113 & 2014 & $<0.000$ \\
\hline $65-84$, large, w/hospital & 2562 & 2461 & 2788 & 2655 & 2696 & 2658 & $<0.000$ \\
\hline $85+$, small & 1175 & 1288 & 1424 & 1294 & 1456 & 1282 & $<0.000$ \\
\hline $85+$, medium and large & 1688 & 1872 & 1977 & 2147 & 2094 & 1935 & $<0.000$ \\
\hline $85+$, medium and large, highest mortality & 1941 & 1759 & 2097 & 1938 & 1931 & 1899 & $<0.000$ \\
\hline All & 1680 & 1814 & 1923 & 1894 & 1988 & 1836 & $<0.000$ \\
\hline \multicolumn{8}{|l|}{ Rate of GP consultations (visits/1000 inhabitants) $\dagger$} \\
\hline \multicolumn{8}{|l|}{ Men } \\
\hline 65-84, small and medium+large non-hospital & 3006 & 4216 & 4599 & 5089 & 6738 & 4675 & $<0.001$ \\
\hline 65-84, large, w/hospital & 3720 & 4303 & 4450 & 5330 & 5809 & 4798 & $<0.000$ \\
\hline $85+$, small & 2793 & 3966 & 4724 & 5110 & 7704 & 5525 & $<0.000$ \\
\hline $85+$, medium and large & 3167 & 4175 & 4664 & 5208 & 6703 & 5552 & $<0.000$ \\
\hline $85+$, medium and large, highest mortality & 3443 & 4221 & 4888 & 5427 & 6521 & 5700 & $<0.000$ \\
\hline All & 2977 & 4174 & 4626 & 5135 & 7052 & 4963 & $<0.000$ \\
\hline \multicolumn{8}{|l|}{ Women } \\
\hline 65-84, small and medium+large non-hospital & 3195 & 4386 & 4611 & 5101 & 6257 & 4655 & $<0.000$ \\
\hline 65-84, large, w/hospital & 3965 & 4442 & 4684 & 5113 & 5237 & 4755 & $<0.000$ \\
\hline $85+$, small & 2856 & 4034 & 4756 & 5096 & 6828 & 4307 & $<0.000$ \\
\hline $85+$, medium and large & 3534 & 4137 & 4599 & 5257 & 6268 & 4579 & $<0.000$ \\
\hline $85+$, medium and large, highest mortality & 3335 & 3998 & 4614 & 4580 & 5192 & 4040 & $<0.000$ \\
\hline All & 3107 & 4270 & 4653 & 5105 & 6343 & 4551 & $<0.000$ \\
\hline \multicolumn{8}{|l|}{ Population (n) } \\
\hline \multicolumn{8}{|l|}{ Men } \\
\hline 65-84, small and mediu m+large non-hospital & 45699 & 29714 & 23547 & 25621 & 43105 & 167686 & $<0.000 \ddagger$ \\
\hline 65-84, large, w/hospital & 19961 & 38927 & 18477 & 23246 & 12197 & 112808 & \\
\hline $85+$, small & 2757 & 1196 & 1733 & 1364 & 6678 & 13728 & \\
\hline $85+$, medium and large & 611 & 617 & 2641 & 8024 & 6191 & 18084 & \\
\hline $85+$, medium and large, highest mortality & 308 & 215 & 355 & 431 & 733 & 2042 & \\
\hline All & 69336 & 70669 & 46753 & 58686 & 68904 & 314348 & \\
\hline \multicolumn{8}{|l|}{ Women } \\
\hline 65-84, small and medium+large non-hospital & 42513 & 30253 & 32049 & 35683 & 49572 & 190070 & $<0.001 \ddagger$ \\
\hline 65-84, large, w/hospital & 12931 & 24016 & 51299 & 34447 & 17959 & 140652 & \\
\hline $85+$, small & 9821 & 4357 & 4769 & 4606 & 5887 & 29440 & \\
\hline $85+$, medium and large & 6816 & 15261 & 9439 & 7557 & 2342 & 41415 & \\
\hline $85+$, medium and large, highest mortality & 1814 & 2168 & 1225 & 422 & 361 & 5990 & \\
\hline All & 73895 & 76055 & 98781 & 82715 & 76121 & 407567 & \\
\hline \multicolumn{8}{|c|}{ Travel time between municipality and hospital (minutes) } \\
\hline \multicolumn{8}{|c|}{ All } \\
\hline 65-84, small and medium+large non-hospital & 63 & 52 & 56 & 53 & 58 & 58 & $<0.000$ \\
\hline 65-84, large, w/hospital & 3 & 4 & 4 & 6 & 3 & 4 & $<0.000$ \\
\hline $85+$, small & 74 & 57 & 51 & 64 & 59 & 64 & $<0.000$ \\
\hline $85+$, medium and large & 5 & 7 & 7 & 9 & 10 & 8 & $<0.000$ \\
\hline $85+$, medium and large, highest mortality & 4 & 7 & 8 & 5 & 7 & 6 & $<0.000$ \\
\hline All & 63 & 47 & 47 & 48 & 54 & 55 & $<0.000$ \\
\hline \multicolumn{8}{|l|}{ All cause mortality rates (total deaths/1000 habitants) } \\
\hline \multicolumn{8}{|l|}{ All } \\
\hline 65-84, small and medium + large non-hospital & 33 & 34 & 37 & 32 & 42 & 36 & $<0.000$ \\
\hline $65-84$, large, w/hospital & 36 & 36 & 28 & 40 & 32 & 35 & $<0.000$ \\
\hline
\end{tabular}


Table 2 Continued

\begin{tabular}{lrrrrrrrr}
\hline & \multicolumn{1}{c}{ GP quintile } & & & & & \\
\cline { 2 - 8 } Age and municipality type & $\mathbf{1}$ & $\mathbf{2}$ & $\mathbf{3}$ & $\mathbf{4}$ & & $\mathbf{5}$ & All & $\mathbf{p}$ Value \\
\hline $85+$, small & 181 & 192 & 178 & 182 & 235 & 201 & $<0.000$ \\
$85+$, medium and large & 137 & 153 & 150 & 164 & 165 & 156 & $<0.000$ \\
$85+$, medium and large, highest mortality & 243 & 258 & 220 & 260 & 377 & 285 & $<0.000$ \\
All & 81 & 81 & 80 & 81 & 110 & 90 & $<0.000$ \\
\hline
\end{tabular}

${ }^{*}$ Tested with one-way analysis of variance.

†Absolute rates of general practitioner (GP) consultations in each defined strata.

$\ddagger$ Tested with $\chi^{2}$ test.

resulting in five strata (figure 1). Crude stratified analyses showed (figure 2), a statistically significant positive $\mathrm{t}$ for the 'Age group 65-84 small to medium \& large non-hospital municipalities'-stratum, the 'Age group 85+ small, no hospital-stratum, and for the 'Age-group $85+$ medium-large'-stratum. For the remaining two strata, the association was also positive, but not statistically significant.

We then identified two significant confounders: (1) sex and (2) travel time to hospital. In the fully adjusted model (figure 2 and table 3), the three strata with statistically significant positive association in crude stratified analysis showed a statistically significant positive trend comparing top and bottom quintiles $(\mathrm{p}<0.0001)$.

The $85+$ stratum with medium and large municipalities and the highest mortality now became a negative but still non-significant association $(\mathrm{p}<0.07)$. The $85+$ stratum for small municipalities without a hospital had a considerably lower OPC rate than all the other groups. This was between $24 \%$ and $39 \%$ lower than the OPC-rates of the stratum aged $85+$ living in medium/larger municipalities.

\section{DISCUSSION}

The principal finding was a moderate positive association between GP consultation rates and rates of OPC use among elderly people in Norway in 2009. The main explanatory variable showed effect modification with age, mortality and the composite of hospital status and municipality population size. The positive association remained when the analysis was adjusted for the two confounding variables-sex and travel time to hospitalexcept in the oldest age group with the highest mortality in medium-large municipalities. Socioeconomic variables did not influence the association, and were not included in the final analysis.

\section{Strengths and limitations}

In Norway, the gate keeping principle requires that GPs send most referrals, in the first instance, to an OPC or private specialist for a specialist evaluation, where further decisions about diagnostic procedures, treatments, follow-up and referrals to other specialised personnel are made. About $90 \%$ of referrals to public OPCs and most referrals to private specialists are non-urgent, and the large OPC volume shows geographical variation. ${ }^{11}$ Consequently, the use of OPCs and specialists is a reliable indicator of the total healthcare use resulting from GP activities. Our comprehensive and high-quality, 1-year dataset offers a suitable base to study associations between explanatory factors and OPC use for older people in a universal healthcare system. By developing regression models using municipality, age and sex specific strata, we were able to examine age and sex effect modification in the age group mostly focused, namely elderly people. Available geographical, socioeconomic and demographic variables known to influence healthcare use made it possible to adjust for municipality and population characteristics.

As the Norwegian healthcare system has given PHC a high priority over the last decade, the findings have relevance for other countries planning to strengthen their PHC. Norway's 430 municipalities (2009) are well-defined administrative units, most frequently used in public statistics and responsible for the provision of PHC, including GPs. The municipalities are responsible for and provide the financial and organisational framework for primary care in Norway. Thus, the municipality level of aggregation allows us to draw conclusions at the healthcare unit level, but not at the individual level. GPs send their consultation data to the Norwegian Health Economics Administration (HELFO) for financial reimbursement. As $99.6 \%$ of the population are registered by a GP as list patients, data on GP consultations are considered complete and of acceptable quality. In addition, the dataset comprises the total number of consultations from almost all casualty clinics.

In Norway, specialist care is offered within a hospital setting that is both publicly funded and organised ('public'), and among private specialists that is privately organised but predominately publicly funded ('private'). The hospital OPC data include both 'public' and 'private' specialist consultations.

Due to data restrictions we undertook this analysis at an aggregate level, and therefore our results might by limited by the ecological fallacy if the area based associations we observed do not hold at the individual level. Nevertheless the hypothesis that we were testing is area based in nature as we are interested in exploring associations at system level that equates to that at which policies 


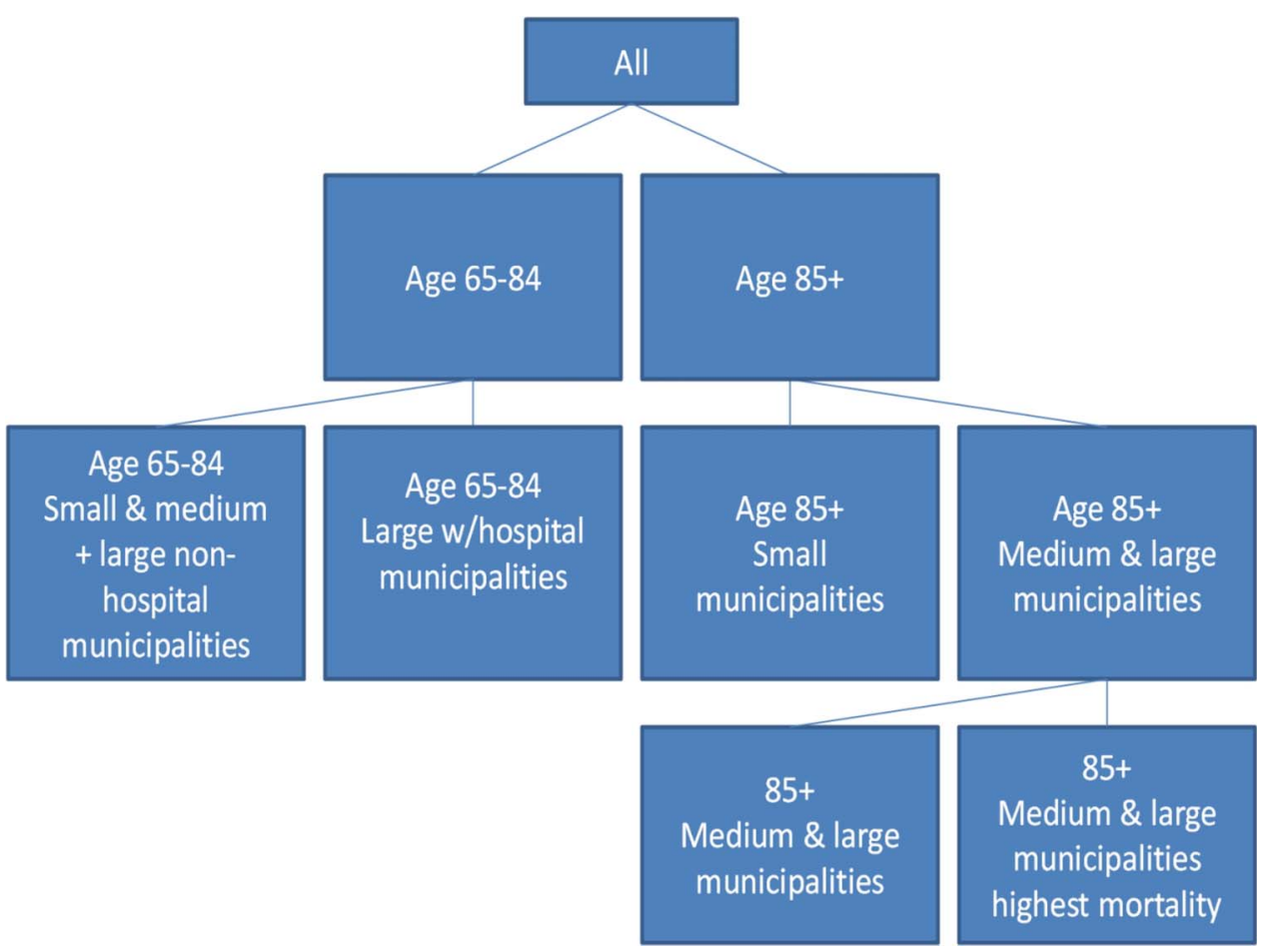

Figure 1 Diagram of stratification by age, the composite variable of municipal 'hospital status' and 'population size' and mortality.

are implemented, so we argue that such aggregate analysis is appropriate in this case. A further limitation is that we only had data for a single time point, and hence interpretation of our findings should be made in light of the limitations of cross-sectional analyses for the determination of causality.

As no information of morbidity was available, we utilised all-cause mortality as a proxy for morbidity. This has limitations, as have other studies in this field, ${ }^{13}$ while some present only crude analyses. ${ }^{19}$ Some authors who have adjusted for morbidity in their analyses found little or no effect of morbidity adjustment on the association between GP volume and utilisation measures. ${ }^{8}{ }^{20}{ }^{21}$ We therefore believe that further adjustment of morbidity in our analyses would not have materially changed our findings.

Except for the highest GP quintile, mortality did not increase with GP quintiles, which is perhaps surprising. Nevertheless, while mortality was an effect modifier, the fact that it did not confound the associations we observed that its use in place of information on morbidity is unlikely to have introduced any significant bias into our analysis.

Over $90 \%$ of the 'private' specialists have delivered their consultation data for 2009. As $30 \%$ of all OPC consultations are 'private' in the dataset, the total OPC rates are slightly underestimated. We have no reason to believe that non-reporting of private OPCs is in any way related to GP consultation rates. Thus, we believe that this data error is random, although it may cause an underestimate of the observed positive relationships.

Overall, we believe that the limitations listed above do not threaten the conclusions in this study.

\section{Previous research}

Two American studies found a non-significant negative association between OPC use and the primary care physician:specialist ratio (PCP-ratio) or primary care physician density, respectively. ${ }^{14}{ }^{15}$ In the USA several specialists (internists, family practitioners (GPs), paediatricians, obstetricians and gynaecologists) work as primary care physicians. About $44 \%$ of the consultations inside US PHC in 2007 were estimated to take place at specialists in family medicine/general practice, who are shown to have different values and goals from other specialists inside PHC. ${ }^{22}{ }^{23}$ Hence, the US studies on the association between PHC and hospital use might be difficult to translate into European or Norwegian contexts, where GPs are the only primary care physicians. The PCP-ratio and 'physician density', used mostly in the American studies as explanatory variables for hospital use, are indirect primary care measures. Whether they are reliable proxies for the primary care activity is unclear. As variations in geography and demography influence both the coverage of GPs and the PCP-ratio, we have instead used a direct measure of the primary care delivered, namely the GP consultation rate (GP rate). Other studies have rarely focused specifically on the use of OPCs, which is the measure that we believe is the 'gate' leading to most of the other non-urgent specialist care activities in the Norwegian setting.

A Danish study, including referrals from 141 GPs to specialists, showed that a higher consultation rate was associated with more overall hospital use. ${ }^{24}$ In contrast to this, a Swedish cross-sectional study from four hospital districts including 52 health centres showed that high 
Figure 2 Crude (above) and adjusted (below) associations between general practitioner consultation and outpatient consultation rates. Stratified by age, the composite variable of municipal 'hospital status' and 'population size' and mortality. First quintile group represents the $20 \%$ lowest percentage in each 5-year age group. Accounted for repeated measures within municipality. Adjusted for sex, travel time to hospital and repeated measures within municipality. Norwegian population aged $\geq 65$ years. 2009 .
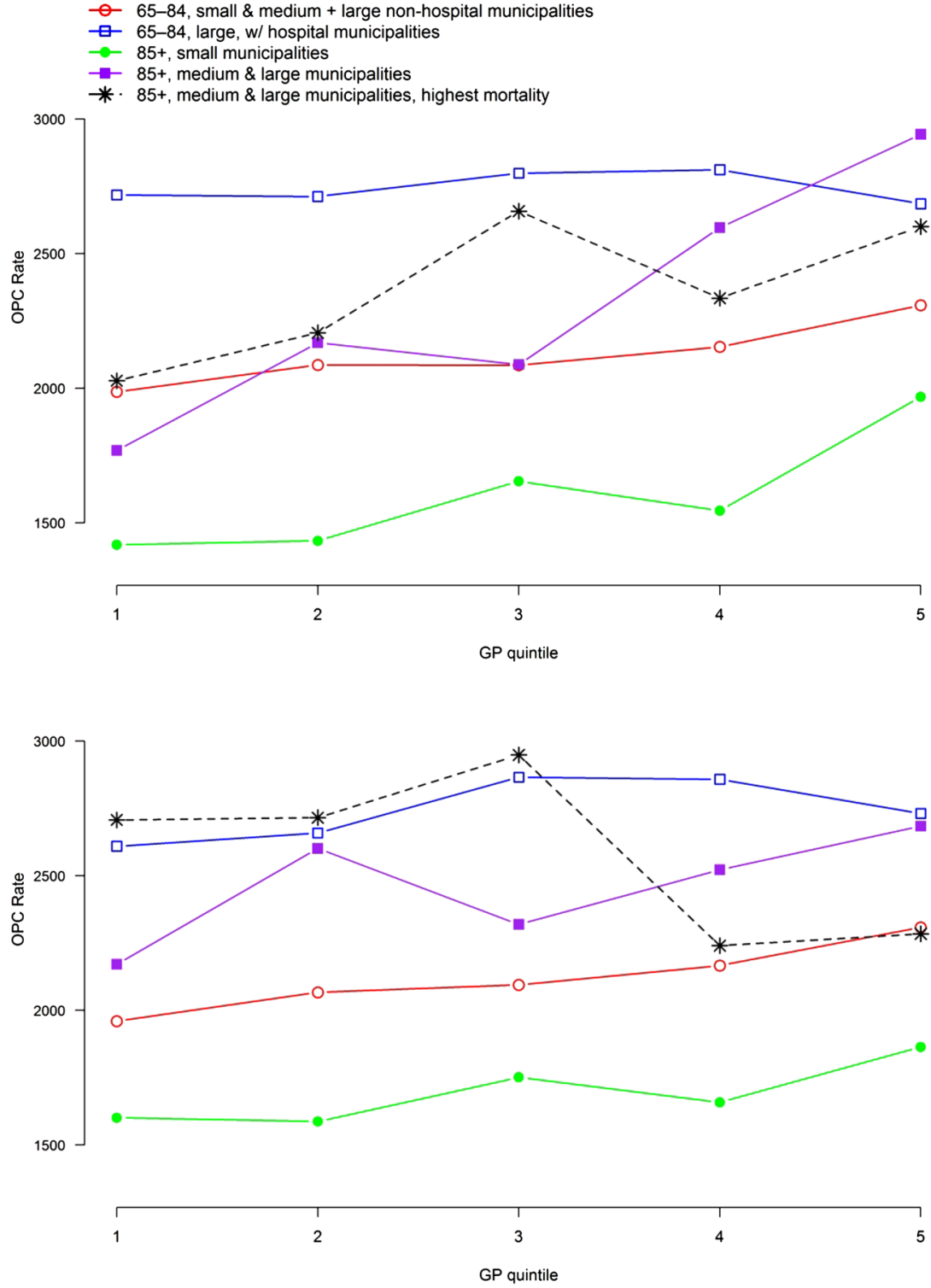

rates of GP visits were associated with reduced hospitalisation. $^{25}$ These studies were undertaken in health systems that have many similarities with the Norwegian system, but the sample sizes were small. Kronman et $a l^{26}$ showed, in an American study of end-of-life primary care visits, that six or more GP visits had a possibly preventive effect on hospital use, thus indicating a GP effect above a certain threshold.

\section{Interpretation of the results}

The major finding is that higher GP activity is associated with higher OPC activity among people 65 years and older. This contradicts other studies demonstrating an overall more efficient healthcare system in countries where GPs are gatekeepers to specialised healthcare. ${ }^{27}$ Whether the strengthened bond between GPs and patients due to the patient list system has led to an even stronger GP emphasis on the patient advocate role at the expense of the gate keeper role is currently under debate. $^{8} 2829$ A study from Danish healthcare, highly comparable to the Norwegian healthcare system, reports an significant higher GP propensity to refer to secondary care in 2009 compared with 1993, mostly to OPC. ${ }^{30}$

Probably, both medical and technical development, increased comorbidity with age, ${ }^{31}$ a stronger population risk awareness, ${ }^{32} 33$ a growing tendency towards disease mongering ${ }^{34}$ and defensive medicine, ${ }^{35} 36$ indicating more intensive therapeutic examinations and/or follow-up ${ }^{37}$ are all factors that probably influence both the GP and the OPC activity and hence the studied association.

Strengthening the supply of and access to a GP may replace specialist care in societies with deficits and inequalities in healthcare. However, above a certain level, for example, in Norway with relatively high rates for both GPs and OPCs, there might be no further substitution effect of increasing GP availability without more clearly defining the organisation and content of the services. This must include a consideration on how GPs 
Table 3 Outpatient consultations per 1000 inhabitants (OPC rate) by general practitioner consultations per 1000 inhabitants (GP rate) quintiles stratified by age and municipality type $†$

\begin{tabular}{|c|c|c|c|c|c|}
\hline \multicolumn{3}{|l|}{ Age 65-84 } & \multicolumn{3}{|l|}{ Age 85+ } \\
\hline Municipality type & $\begin{array}{l}\text { Small and medium } \\
+ \text { large non-hospital }\end{array}$ & Large, w/hospital & Small & Medium and large & $\begin{array}{l}\text { Medium and large, } \\
\text { highest mortality }\end{array}$ \\
\hline \multicolumn{6}{|l|}{ GP quintile } \\
\hline 1 & $\begin{array}{l}1960 \\
\text { (1904 to 2015) }\end{array}$ & $\begin{array}{l}2609 \\
\text { (2354 to 2865) }\end{array}$ & $\begin{array}{l}1601 \\
\text { (1526 to } 1676)\end{array}$ & $\begin{array}{l}2171 \\
\text { (1944 to } 2398)\end{array}$ & $\begin{array}{l}2707 \\
\text { (2434 to 2980) }\end{array}$ \\
\hline 2 & $\begin{array}{l}2067 \\
\text { (2008 to 2126) }\end{array}$ & $\begin{array}{l}2658 \\
\text { (2467 to 2849) }\end{array}$ & $\begin{array}{l}1587 \\
\text { (1483 to } 1691)\end{array}$ & $\begin{array}{l}2601 \\
\text { (2406 to 2795) }\end{array}$ & $\begin{array}{l}2715 \\
(2450 \text { to } 2980)\end{array}$ \\
\hline 3 & $\begin{array}{l}2094 \\
\text { (2035 to } 2153)\end{array}$ & $\begin{array}{l}2865 \\
\text { (2682 to } 3049)\end{array}$ & $\begin{array}{l}1751 \\
(1656 \text { to } 1846)\end{array}$ & $\begin{array}{l}2319 \\
\text { (2138 to } 2500)\end{array}$ & $\begin{array}{l}2948 \\
\text { (2653 to } 3243)\end{array}$ \\
\hline 4 & $\begin{array}{l}2166 \\
\text { (2108 to 2224) }\end{array}$ & $\begin{array}{l}2858 \\
\text { (2677 to } 3039 \text { ) }\end{array}$ & $\begin{array}{l}1658 \\
(1562 \text { to } 1755)\end{array}$ & $\begin{array}{l}2522 \\
\text { (2363 to 2681) }\end{array}$ & $\begin{array}{l}2240 \\
(1860 \text { to } 2620)\end{array}$ \\
\hline 5 & $\begin{array}{l}2308 \\
\text { (2252 to 2364) }\end{array}$ & $\begin{array}{l}2731 \\
\text { (2491 to 2971) }\end{array}$ & $\begin{array}{l}1864 \\
(1790 \text { to } 1938)\end{array}$ & $\begin{array}{l}2684 \\
\text { (2488 to 2879) }\end{array}$ & $\begin{array}{l}2284 \\
\text { (1947 to 2621) }\end{array}$ \\
\hline Diff $1-5$ & $\begin{array}{l}-348^{\star \star \star} \\
(-427 \text { to }-269)\end{array}$ & $\begin{array}{l}-122 \\
(-474 \text { to }-231)\end{array}$ & $\begin{array}{l}-263^{\star \star \star} \\
(-368 \text { to }-157)\end{array}$ & $\begin{array}{l}-512^{\star \star \star} \\
(-811 \text { to }-213)\end{array}$ & $\begin{array}{l}-423 \\
(-29 \text { to } 875)\end{array}$ \\
\hline
\end{tabular}

could be used more effectively, and how GPs can be included in chronic care management.

The absolute level of OPC use is substantially lower in the smaller and more distant municipalities (mean travel time approximately $1 \mathrm{~h}$ ) for all age groups (table 2). We hypothesise that distance may be a barrier to secondary care. Whether this reflects an adequate pattern of use is unknown, but it is likely that these municipalities organise and integrate the total PHC system for elderly people differently. Two Canadian studies support such an interpretation. $^{38} 39$ One Canadian qualitative study indicated that lower referral rates from distant municipalities can mostly be explained by access to local resources and corresponding practice styles that influence the local ecology of total healthcare use. ${ }^{40}$

The OPC utilisation differences between the highest and lowest GP percentiles are between $10 \%$ and $15 \%$, highest for the oldest groups. The difference is close to what we a priori defined as relevant to policy, although we are not able to define the optimal level of the OPC-rate. Whether this reflects a quality improvement potential among some GPs, is outside the scope of the study. However, a recently published English report states that albeit a general good-quality, wide variation in performance and quality of care indicate an opportunity for quality improvement in general practice. ${ }^{41}$

The negative association found for the 85+ group with the highest mortality might illustrate that a higher GP presence meets the patient needs in this group better when in cooperation with municipal long-term care. Also, patients with a high morbidity might be referred directly to hospital inpatient care instead of an OPC. As the $85+$ group with high mortality consists of $1.1 \%$ of the population of the dataset, we cannot exclude that the finding is a result of unstable data (table 2).

\section{Further research}

Characteristics of the healthcare system, case-mix and living conditions (geographical, cultural and socioeconomic) have an impact on the small area variations in healthcare use. $^{42}$ In Norway, with moderate socioeconomic and mortality inequalities, we find that the variability in use of specialist care is explained by both differences in case-mix and variations at the municipal and healthcare level. There is a need for data that allow the analysis of individuals and higher level units simultaneously, preferably over time. This analysis necessitates adequate statistical frameworks, such as multilevel modelling. In addition we need legal and practical access to existing data sources at the individual and GP level, including information on multimorbidity and referrals that facilitates research on patient trajectories.

We conclude that more of the same GP service will hardly ease the pressure on secondary care in a setting with universal healthcare coverage and high GP-accessibility. A reduction in secondary care utilisation may be a joint product of both high GP access and a reorganisation of care, according to new principles of chronic care management. If so, health workers, including GPs and specialists, should consider to reorganise, redistribute and delegate some of their clinical work ${ }^{43}$ and participate or take the lead in collaborative care networks in partnership with some of their patients. However, implementing models for integrated chronic care is hard work, ${ }^{44}$ and might suffer from single disease-orientated rather than person-focused models, as many patients are multimorbid. ${ }^{45}$ Complex daily practices, ${ }^{47}$ interprofessional attitudes ${ }^{48}$ and insufficient management skills, ${ }^{49}$ are challenges which need to be focused both in development of such teams and in education and continued training for health personnel in the future. ${ }^{50}$ As such models are not necessarily transferable, 
they have to be developed and evaluated multidimensionally in a Scandinavian setting. How this will influence the utilisation and costs of primary and secondary care is a subject for research.

\section{CONCLUSIONS}

A high GP consultation rate in Norway is associated with increased use of specialised outpatient healthcare. This finding suggests that, in a universal health insurance system with high GP-accessibility, it is unlikely that a health policy focusing only on a higher volume of GP consultations will decrease pressure on SHC use among elderly people.

Acknowledgements The authors would like to thank researcher Erik $\mathrm{R}$ Sund, Regional Health Authority of Northern Norway and Professor Andy Jones, University of East Anglia, for valuable comments to the manuscript.

Contributors TSD and GB initiated and designed the study. TSD collected the data. TSD and GB carried out the data analyses. TSD drafted the paper, and all authors contributed to the writing of the manuscript and read and approved the final manuscript. GB is the guarantor of the study.

Funding This work was supported by Regional Health Authority of Northern Norway, and the National Centre of Rural Medicine, Tromsø, Norway.

Competing interests None.

Ethics approval The study was approved by the Privacy Ombudsman for Research in Norway in accordance with the Personal Data Act and Health Registry Act (project number 17869).

Provenance and peer review Not commissioned; externally peer reviewed.

Data sharing statement No additional data are available.

\section{REFERENCES}

1. Australian Government, Department of Health and Aging. A National Health and Hospitals Network for Australia's Future-Delivering better health and better hospitals. 2010. http://www.yourhealth.gov. au/internet/yourhealth/publishing.nsf/Content/report-redbook (accessed 18 Aug 2012).

2. Lavis JN, Shearer JC. Issue brief: strengthening primary healthcare in Canada. Hamilton, Canada: McMaster Health Forum, 2010. http://siasat.behdasht.gov.ir/uploads/291_1797_hr8.pdf (accessed 18 Aug 2012)

3. World Health Organization. The World Health Report 2008: Primary Health Care Now More Than Ever. 2009. http://www.who.int/whr/ 2008/whr08_en.pdf (accessed18 Aug 2012).

4. Sepulveda MJ, Bodenheimer T, Grundy P. Primary care: can it solve employers' health care dilemma? Health Aff (Millwood) 2008;27:151-8.

5. Johnsen JR. Health Systems in Transition: Norway. Copenhagen, WHO Regional Office for Europe on behalf of the European Observatory on Health Systems and Policies. 2006. http://www.euro. who.int/_data/assets/pdf_file/0005/95144/E88821.pdf (accessed 18 Aug 2012)

6. Nerland SM, Hagen T. (Access to speciality health care in Norway: did the hospital reform of 2002 lead to improved equality of access?) (In Norwegian). Tidskrift for samfunnsforskning 2008;49:37-71.

7. Forde $\mathrm{OH}$, Breidablik $\mathrm{HJ}$, Ogar P. (Do differences in referral rates threaten the goal of equity in health care?) (In Norwegian). Tidsskr Nor Laegeforen 2011;131:1878-1.

8. Grytten J, Sorensen R. Practice variation and physician-specific effects. J Health Econ 2003;22:403-18.

9. Atun R. What are the advantages and disadvantages of restructuring a health care system to be more focused on primary care services? Health Evidence Network. WHO Regional Office for Europe, 2004. http://www.euro.who.int/ data/assets/pdf file/0004/74704/E82997. pdf (accessed 18 Aug 2012).

10. Norwegian Ministry of Health and Care Services. (The Coordination Reform: Proper treatment-at the right place and right time) (In Norwegian). 2009. http://www.regjeringen.no/nb/dep/hod/dok/ regpubl/stmeld/2008-2009/stmeld-nr-47-2008-2009-.html?id=567201 (accessed 18 Aug 2012).

11. Norwegian Patient Registry. (Activity based financed stays with rates) (In Norwegian). 2010. http://www.helsedirektoratet.no/ kvalitet-planlegging/norsk-pasientregister-npr/Sider/default.aspx (accessed 18 Aug 2012).

12. Welch WP, Miller ME, Welch HG, et al. Geographic variation in expenditures for physicians' services in the United States. $N$ Engl $J$ Med 1993;328:621-7.

13. Starfield B, Shi L, Macinko J. Contribution of primary care to health systems and health. Milbank Q 2005;83:457-502.

14. Kravet SJ, Shore AD, Miller R, et al. Health care utilization and the proportion of primary care physicians. Am J Med 2008;121:142-8.

15. Wright DB, Ricketts TC III. The road to efficiency? Re-examining the impact of the primary care physician workforce on health care utilization rates. Soc Sci Med 2010;70:2006-10.

16. Eurostat. 31st meeting of the statistical programme commitee Luxembourg, 26 \& 27 November 1998 Item 2 of the Agenda. Recommendations on Social Exclusion and Poverty statistics. http://epp.eurostat.ec.europa.eu/cache/ITY SDDS/Annexes/ tsdec210_esms_an6.pdf. (accessed 18 Aug 2012).

17. Deraas TS, Berntsen GR, Forde OH, et al. Does long-term care use within primary health care reduce hospital use among older people in Norway? A national 5-year population-based observational study. BMC Health Serv Res 2011;11:287.

18. Greenland S, Rothman KJ. Introduction to stratified analyses. In: Greenland S, Rothman KJ, eds. Modern epidemiology. 2nd edn. New York: Lippincot-Raven Publishers, 1998:253-79.

19. Baicker K, Chandra A. Medicare spending, the physician workforce, and beneficiaries' quality of care. Health Aff. Published Online First 7 April 2004; doi:10.1377/hlthaff.w4.184 (accessed 18 Aug 2012).

20. Gulliford MC. Availability of primary care doctors and population health in England: is there an association? J Public Health 2002;24:252-4

21. Mark DH, Gottlieb MS, Zellner BB, et al. Medicare costs in urban areas and the supply of primary care physicians. J Fam Pract 1996;43:33-9.

22. National Health Statistics Reports. National ambulatory medical care survey: 2007. Centers for disease control and prevention, 2010;27:1-32. http://www.cdc.gov/nchs/data/nhsr/nhsr027.pdf (accessed 18 Aug 2012).

23. Lipsky MS, Sharp LK. Exploring the mission of primary care. Family Med 2006;38:121-5.

24. Christensen B, Sorensen HT, Mabeck CE. Differences in referral rates from general practice. Fam Pract 1989;6:19-22.

25. Lindstrom K, Engstrom S, Bengtsson C, et al. Determinants of hospitalisation rates: does primary health care play a role? Scand $J$ Prim Health Care 2003;21:15-20.

26. Kronman AC, Ash AS, Freund KM, et al. Can primary care visits reduce hospital utilization among Medicare beneficiaries at the end of life? J Gen Intern Med 2008;23:1330-5.

27. Bhat VN. Institutional arrangements and efficiency of health care delivery systems. Eur J Health Econom 2005;6:215-22.

28. Carlsen B, Norheim O. 'Saying no is no easy matter': a qualitative study of competing concerns in rationing decisions in general practice. BMC Health Serv Res 2005;5:70.

29. Tjerbo T. Does competition among general practitioners increase or decrease the consumption of specialist health care? Health Econ Policy Law 2010;5(Pt 1):53-70.

30. Moth G, Olesen F, Vedsted P. Reasons for encounter and disease patterns in Danish primary care: changes over 16 years. Scand $J$ Prim Health Care 2012;30:70-5.

31. Wolff J, Starfield B, Anderson G. Prevalence, expenditures and complications of multiple chronic conditions in the elderly. Arch Intern Med 2002;162:2269-76.

32. Lupton D. Risk as moral danger: the social and political functions of risk discourse in public health. Int J Health Serv. 1993;23:425-35.

33. Forde $\mathrm{OH}$. Is imposing risk awareness cultural imperialism? Soc $\mathrm{Sci}$ Med 1998;47:1155-9.

34. Moynihan R, Henry D. The fight against disease mongering: generating knowledge for action. PLoS Med 2006;3e191.

35. Anderson RE. Billions for defense: the pervasive nature of defensive medicine. Arch Intern Med 1999;159:2399-402.

36. Ray M, Jenny D, David H. Preventing overdiagnosis: how to stop harming the healthy. BMJ 2012;344.

37. Bishop TF, Federman AD, Keyhani S. Physicians' views on defensive medicine: a national survey. Arch Intern Med 2010;170:1081-3.

38. Allan D, Cloutier-Fisher D. Health service utilization among older adults in British Columbia: making sense of geography. Can J Aging 2006;25:219-32. 
39. McDonald JT, Conde H. Does geography matter? The health service use and unmet health care needs of older Canadians. Can J Aging 2010;29(Special issue 1):23-37.

40. Langley G, Minkin S, Till JE. Regional variation in nonmedicalfactors affecting family physicians' decisions about referral for consultation. Can Med Assoc J 1997;157:265-72.

41. King's Fund. Improving the quality of care in general practice. Report of an independent inquiry commissioned by The King's Fund. King's Fund, 2011:1-155.

42. Rosenthal T. Geographic variation in health care. Annu Rev Med 2012;63:493-509.

43. Bitton A. Who is on the home team? Redefining the relationship between primary and specialty care in the patient-centered medical home. Med Care 2011:49:1-3.

44. Jackson GL, Weinberger M. A decade with the chronic care model: some progress and opportunity for more. Med Care 2009;47:929-31.
45. Starfield B. Point: the changing nature of disease: implications for health services. Med Care 2011;49:971-2.

46. Wagner EH. Counterpoint: chronic illness and primary care. Med Care 2011:49:973-5.

47. Crabtree BF, Nutting PA, Miller WL, et al. Primary care practice transformation is hard work: insights from a 15-year developmental program of research. Med Care 2011;49(Suppl): S28-35.

48. Braithwaite J, Westbrook M, Nugus $\mathrm{P}$, et al. A four-year systems-wide intervention promoting interprofessional collaboration. BMC Health Serv Res 2012;12:99.

49. Bohmer R. Managing the new primary care: the new skills that will be needed. Health Aff 2010;29:1010-14.

50. Schuetz B, Mann E, Everett W. Educating health professionals collaboratively for team-based primary care. Health Aff (Millwood) 2010;29:1476-80 


\section{Correction}

Deraas TS, Berntsen GR, Hasvold T, et al. Is a high level of general practitioner consultations associated with low outpatients specialist clinic use? A cross-sectional study. BMJ Open 2013;3: e002041. There are two typographical errors in this article:

The first error appears on page 5, at the end of the Results section. ' $\mathrm{p}=0.07$ ' was incorrectly written as ' $\mathrm{p}<0.07$ ' in the sentence 'The $85+$ stratum with medium and large municipalities and the highest mortality now became a negative but still non-significant association $(p<0.07)$ '.

The second error appears in table 3, in row 'Diff 1-5', column 'Medium and large, highest mortality'. ' -423 ' should be ' +423 '.

BMJ Open 2013;3:e002041corr1. doi:10.1136/bmjopen-2012-002041corr1 